\title{
Simultaneous quantification of teneligliptin hydrobromide and metformin hydrochloride: an improved HPTLC method with implementation of Plackett-Burman design
}

\author{
Mehul Patel $\oplus^{1 *}$, Divya Patel $\oplus^{1}$, Umang Shah ${ }^{1}{ }^{1}$ and \\ Heta Kachhiya ${ }^{2}$ \\ ${ }^{1}$ Ramanbhai Patel College of Pharmacy, Charotar University of Science and Technology, CHARUSAT \\ Campus, Changa - 388 421, Ta. Petlad, Dist. Anand, Gujarat, India \\ ${ }^{2}$ Indukaka Ipcowala College of Pharmacy, Charutar Vidyamandal University, New V.V.Nagar-388001, \\ Ta. Anand, Dist. Anand, Gujarat, India
}

(Received November 28, 2020; Revised January 05, 2021; Accepted January 07, 2021)

\begin{abstract}
Simple, rapid, sensitive, robust, and validated high-performance thin-layer chromatography was developed for the simultaneous estimation of anti-diabetic drugs Teneligliptin hydrobromide (TH) and Metformin hydrochloride (MH) in bulk and pharmaceutical formulation. HPTLC system equipped Camag Linomat V, TLC Scanner IV, Twin Trough chamber, Dual-wavelength UV Cabinet, and win CATS software V1.4.7 were used during the study. Separation of analytes was achieved using a pre-coated silica gel G60 F254 aluminum sheets $10 \times 10 \mathrm{~cm}^{2}$, with the thickness of $0.2 \mathrm{~mm}$ as stationary phase and a mobile phase comprising of Methanol: Ammonium sulfate $(0.5 \% \mathrm{w} / \mathrm{v})$ : Triethylamine (9: 2.7: $0.5 \mathrm{v} / \mathrm{v} / \mathrm{v})$. The detection wavelength was set at $237 \mathrm{~nm}$. The $\mathrm{R}_{\mathrm{f}}$ value of the $\mathrm{TH}$ and $\mathrm{MH}$ was 0.63 and 0.19 , respectively. The method was validated using a dynamic linear range of $4-28 \mathrm{ng} / \mathrm{band}$ and 100-700 $\mathrm{ng} / \mathrm{b}$ and for $\mathrm{TH}$ and $\mathrm{MH}$, respectively. The developed method was validated as per the ICHQ2 (R1) guideline. The statistical analysis proved that the process is accurate with $98.80-99.38 \% \mathrm{w} / \mathrm{v}$ and $99.66-99.96 \% \mathrm{w} / \mathrm{v}$ for TH and $\mathrm{MH}$, respectively, and precise with less than $2 \%$ RSD. The Plackett-Burman design was applied to check the robustness of the developed method. Finally, the method is termed as linear, precise, accurate, and robust. It can be implemented successfully for the routine analysis of pharmaceutical dosage forms comprising $\mathrm{TH}$ and $\mathrm{MH}$ and is appropriate for regulatory submission under regulatory flexibility.
\end{abstract}

Keywords: Teneligliptin hydrobromide; metformin hydrochloride; high-performance thin-layer chromatography; ICH guidelines; simultaneous estimation; quality by design. ( 2021 ACG Publications. All rights reserved.

\section{Introduction}

Teneligliptin, a novel dipeptidyl peptidase 4 inhibitor, recently approved for the treatment of diabetes mellitus (Type $2 \mathrm{DM})$. Chemically it is [(2S,4S)-4-[4-(5-methyl-2-phenyl pyrazole-3-yl)piperazin1-yl]pyrrolidin-2-yl]-(1,3-thiazolidine-3-yl)methanone;hydrate;hydrochloride [1]. Metformin is a derivative of a biguanide, and for many years, it is prescribed as an oral anti-diabetic drug. It is a drug of choice for the management of type 2 diabetes mellitus. It acts by reducing glucose production by the liver. Chemically it is 3-(diaminomethylidene)-1,1-dimethylguanidine (Figure 1). The combination of Teneligliptin and Metformin with adjunct to diet and exercise, plays an important role in controlling the glycemic level.

\footnotetext{
* Corresponding author E-Mail: mehulpatel.ph@charusat.ac.in
} 
For the quality control aspects, it is essential to develop analytical methods for such combination products [2]. Various sophisticated analytical techniques are described in the literature to analyze Metformin and Tenelegliptine either individually or in combination with other drugs by UV Spectrometry method [3-4], HPLC [5-11], Ultrafast LC method [12-13], LC-MS/MS methods [14-16], Stability indicating HPLC method [17] and HPTLC method [18-20]. However, the HPTLC analytical method for simultaneous estimation of Metformin and Tenelegliptine is not available. So Precise, accurate, and sensitive method for simultaneous determination of TH and MH using HPTLC was planned and validated as per Q2 (R1) guideline.

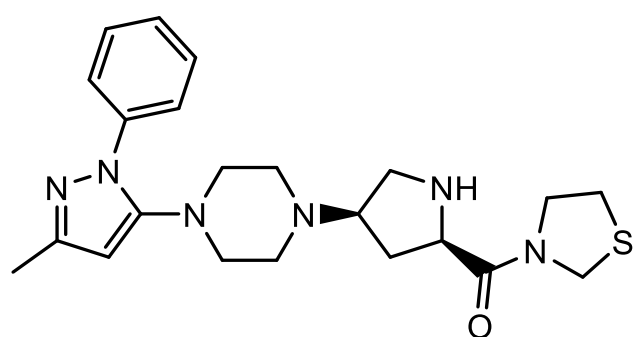

Teneligliptin<smiles>CN(C)C(=N)NC(=N)N</smiles>

Metformin

Figure 1. Chemical structures of Teneligliptin (TH) and Metformin (MH)

Robustness testing is an essential part of analytical method validation. It generally determines an analytical method or procedure's capacity, which remains unbiased while changing the experimental condition. Robustness is essential because sometimes small variations in the experimental parameters or process make considerable differences in results. The analyst needs to develop such a method to not affect the method's accuracy by these minor experimental conditions. For the robustness evaluation, the two-level factorial design is considered the most suitable. However, fractional factorial design, like Plackett-Burman designs, has been employed in robustness evaluations [21-23]. By looking at the above consideration, it was planned to assess robustness parameter using widely accepted Plackett-Burman designs

\section{Experimental}

\subsection{Materials and Methods}

Quantitative HPTLC was performed on liquid chromatography, Camag Linomat V, Hamilton Syringe $(100 \mu \mathrm{L})$, Camag TLC Scanner IV (scanning speed up to $100 \mathrm{~mm} / \mathrm{s}$, spectral range $190-800 \mathrm{~nm}$ ), Camang Twin Trough chamber, Dual-wavelength UV Cabinet, and Camag winCATS software V1.4.7. Teneligliptin (TH) is $99.95 \% \mathrm{w} / \mathrm{w}$, and metformin (MH) $99.45 \% \mathrm{w} / \mathrm{w}$ was obtained from Pure Chem Pvt Ltd, Ankleshwar, India. The solvents used methanol, Triethylamine, and Ammonium Sulfate of AR grade were purchased from Loba Chemicals. The tablet of Afoglip M 500 containing $20 \mathrm{mg}$ of TH and $500 \mathrm{mg}$ MH were obtained from a local pharmacy.

\subsection{Selection of Mobile Phase for HPTLC}

In the initial trial, mobile phase comprised of methanol and ammonium sulfate $(5 \% \mathrm{w} / \mathrm{v})(7.5: 2.5$ $\mathrm{v} / \mathrm{v} / \mathrm{v}$ ) was tried but this mobile phase was not suitable for separation of TH and $\mathrm{MH}$. Later on, triethylamine was added into the previous mobile phase, and proportion was set as methanol: ammonium sulfate $(0.5 \% \mathrm{w} / \mathrm{v})$ : triethylamine $(9: 2.5: 0.5 \mathrm{v} / \mathrm{v} / \mathrm{v})$. In this method, both drugs were detected, but peak tailing was found in TH and MH peaks. The method was then carried out with the mobile phase ammonium sulfate $(1 \% \mathrm{w} / \mathrm{v})$ : methanol: triethylamine $(8: 4.2: 0.4 \mathrm{v} / \mathrm{v} / \mathrm{v})$. All peaks were detected; however, tailing on the peaks were observed. The method was then carried out with the mobile phase consisted of methanol: ammonium sulfate $(0.5 \% \mathrm{w} / \mathrm{v})$ : triethylamine $(9: 2.7: 0.5 \mathrm{v} / \mathrm{v} / \mathrm{v})$. This method gives both peaks better resolution and reproducibility; hence this mobile phase was selected for HPTLC. 


\subsection{Preparation of Solutions}

Preparation of the mobile phase and diluents: Optimized mobile phase consisted of a mixture of methanol: ammonium sulfate $(0.5 \% \mathrm{w} / \mathrm{v})$ : triethylamine in ratio $9: 2.7: 0.5 \mathrm{v} / \mathrm{v} / \mathrm{v}$ respectively.

Wavelength optimization and selection by TLC spots were scanned over $200-400 \mathrm{~nm}$ for optimized wavelength detection. The spectra of TH and MH have been taken for the same. During this exercise, it was considered the $237 \mathrm{~nm}$ for detection of both the drugs.

Stock standard solutions prepared by approximately $10 \mathrm{mg}$ of TH has been precisely weighted and transferred to a $10 \mathrm{~mL}$ volumetric flask and dissolved in $10 \mathrm{~mL}$ of methanol to give a $1000 \mu \mathrm{g} / \mathrm{mL}$ (Solution A) stock prepare a stock solution of $5000 \mu \mathrm{g} / \mathrm{mL}$ (solution B).

Working standard solutions prepared by taking about $2 \mathrm{~mL}$ solution was taken from solution A, and $1 \mathrm{~mL}$ from solution $\mathrm{B}$ in $10 \mathrm{~mL}$ volumetric flask and make up the volume by mark with methanol. This final solution was a concentration of $200 \mu \mathrm{g} / \mathrm{mL}$ of $\mathrm{TH}$ and $500 \mu \mathrm{g} / \mathrm{mL}$ of $\mathrm{MH}$ (Solution C). Another solution was made by taking a $1 \mathrm{~mL}$ solution from solution $\mathrm{C}$ in a $10 \mathrm{~mL}$ volumetric flask and make up the volume by mark with methanol. This solution was of a concentration of $20 \mu \mathrm{g} / \mathrm{mL}$ of TH and $50 \mu \mathrm{g} / \mathrm{mL}$ of MH.

Sample solution for assay was prepared by weighed and crushed twenty tablets. Tablet powder equivalent to $20 \mathrm{mg}$ of $\mathrm{TH}$ and $500 \mathrm{mg}$ of $\mathrm{MH}$ has been transferred to a $100 \mathrm{~mL}$ flask. Twenty milliliters of methanol were added to the volumetric flask and sonicated for $45 \mathrm{~min}$, filtered through Whatman filter paper No. 41, and make up the volume by mark with methanol to prepare solution concentration $200 \mu \mathrm{g} / \mathrm{mL}$ of $\mathrm{TH}$, and $5000 \mu \mathrm{g} / \mathrm{mL} \mathrm{MH}$. From that, $1 \mathrm{~mL}$ solution was transferred to $10 \mathrm{~mL}$ volumetric flask and diluted with methanol to make $20 \mu \mathrm{g} / \mathrm{mL}$ of TH and $500 \mu \mathrm{g} / \mathrm{mL} \mathrm{MH.} 1 \mathrm{~mL}$ solution was further transferred to a $10 \mathrm{~mL}$ volumetric flask and made up the volume by mark with methanol to prepare a solution containing $2 \mu \mathrm{g} / \mathrm{mL}$ of $\mathrm{TH}$ and $50 \mu \mathrm{g} / \mathrm{mL} \mathrm{MH}$.

Working standard solution $(14 \mu \mathrm{L})$ or sample solution for analysis of formulation $(10 \mu \mathrm{L})$ was spotted on the pre-washed TLC plate and developed with mobile phase Methanol: Ammonium sulphate $(0.5 \% \mathrm{w} / \mathrm{v})$ : Triethylamine in ratio 9: $2.7: 0.5 \mathrm{v} / \mathrm{v} / \mathrm{v}$ respectively. With Camag TLC Scanner-V using winCATS V 1.4.7 software, photometric measurements were taken at $237 \mathrm{~nm}$ in the absorbance/reflectiveness mode.

\subsection{Methods}

The sample solution for analysis of formulation $(10 \mu \mathrm{L})$ and standard working solution $(14 \mu \mathrm{L})$ carried out on a pre-washed TLC plate using a semi-automatic spotter under a nitrogen stream.

The IR lamp has been used for drying purposes, and the plate was developed in a saturated chamber for at least 15 min using mobile phase. The oven is used for drying the plate after development. Photometric measurements were taken at $237 \mathrm{~nm}$ in the absorbance/reflectiveness mode incorporating the track optimization option.

A linearity study checks that the sample solutions are within a concentration range where the analytes' response directly relates to concentration. The accuracy was computed using a standard method of addition. The fixed amount of pre-analyzed standard solution was added with a known amount of standard drug $[14,24]$. The precision was conducted by intra-day and inter-day precision by using three standard solutions of $\mathrm{TH}$ and MF. Specificity is the method to compare $\mathrm{R}_{\mathrm{f}}$ of the sample solution and standard drug solution [15,25]; however, no interference observed in the separation and resolution of $\mathrm{MH}$ and TH indicates the method is specific. Standard solutions of TH and MH calculated the method's detection limit on the TLC plate. Using the S/N method, the peak-to-peak noise around the analyte retention time is calculated, and subsequently, the analyte concentration that would yield a signal equal to a specific value of noise to signal ratio is measured. An S/N ratio of 3 is generally accepted for estimating LOD, and an $\mathrm{S} / \mathrm{N}$ ratio of 10 is used for estimating LOQ. This method is commonly applied to analytical methods that exhibit baseline noise [16, 25-27].

\subsection{Application of Placket-Burman (PB) design}

The developed HPTLC method validated for robustness using Placket-Burman (PB) design with twelve experiments. Different kind of seven HPTLC trials was planned and analyzed, i.e., modification in 
the proportion of benzene and methanol in mobile phase composition by keeping one of it constant, modification in mobile phase volume, alteration in saturation time, detection at a different wavelength, change selection of bandwidth, modification in a run distance of solvent. Each factor was analyzed at two factorial levels. The study's limitation has been chosen based on the range of errors most commonly observed in an analytical laboratory. The experimental designs for the HPTLC method were create using the Design Expert 9 software. In each experimental condition, the area for TH and MH were observed.

\section{Results and discussion}

\subsection{Chromatographic Separation}

In the development of the HPTLC method, which is accurate, specific, sensitive, and reliable for the aspect of determination of TH and MH in combined dosage form, The Silica gel G60 F254 aluminum sheet $(10 \times 10$ and $10 \times 20 \mathrm{~cm})$ was used as the stationary phase. The mobile phase comprises of methanol: ammonium sulfate $(0.5 \% \mathrm{w} / \mathrm{v})$ : triethylamine in ratio 9: $2.7: 0.5 \mathrm{v} / \mathrm{v} / \mathrm{v}$. Both the drug were detected and scanned at $237 \mathrm{~nm}$. The representative densitogram indicating TH and $\mathrm{MH}$ is displayed in Figure 2.

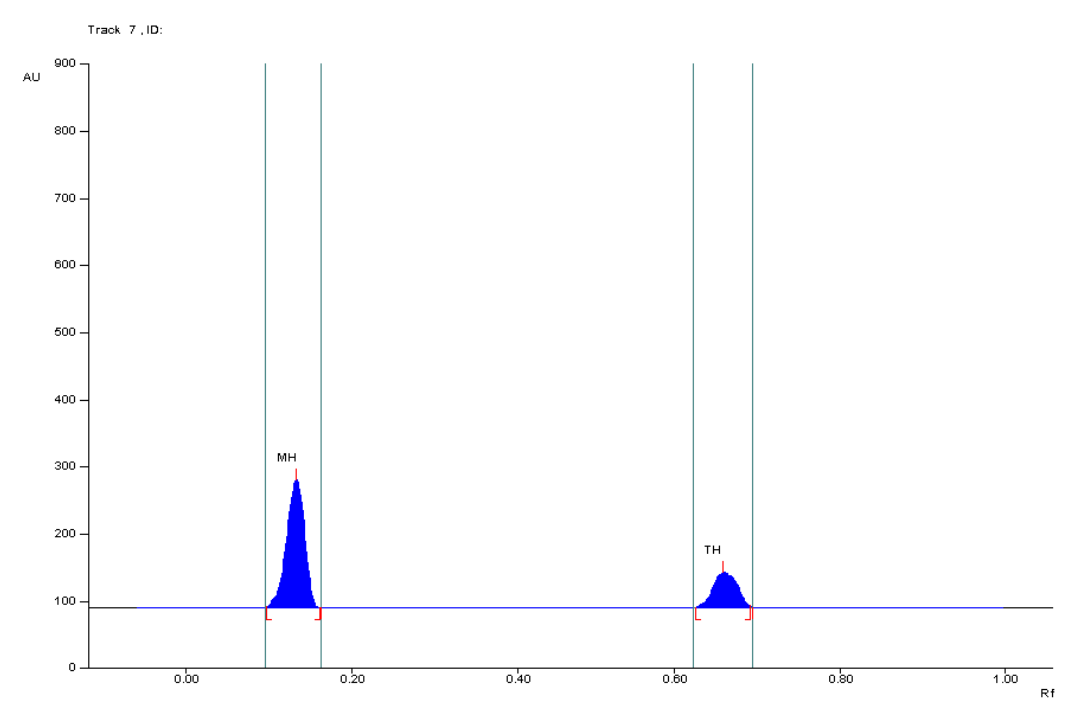

Figure 2. Densitogram of MH (700ng/band) $R_{f}=0.19 \pm 0.3$ and $T H$ ( $28 \mathrm{ng} /$ band) $R_{f}=0.63 \pm 0.2$

In developing methods, the effects of different parameters are carried out by changing parameters one by one and keeping other parameters constant. In the development of this method, a systemic study of the effects of significant parameters was conducted by changing one parameter at a time and controlling all others.

\subsection{Optimized Chromatographic Conditions of TH and MH Parameters}

Based on all the trials, HPTLC separation was optimized on aluminum plates pre-coated with silica gel 60 F254 $\left(10 \times 10 \mathrm{~cm}^{2}\right.$, layer thickness $\left.0.2 \mathrm{~mm}\right)$ as the stationary phase using methanol: ammonium sulphate: triethylamine (9: 2.7: $0.5 \mathrm{v} / \mathrm{v} / \mathrm{v})$ as the mobile phase. Methanol was used as diluent. Entire experiments were carried out at room temperature, and chamber saturation time was kept for 15 minutes. Quantification was achieved based on densitometric analysis of teneligliptin hydrobromide and metformin hydrochloride over the concentration range of 4-28 ng/band and 100-700 ng/band, respectively, at $237 \mathrm{~nm}$. The method yielded compact and well-resolved bands at $\mathrm{R}_{\mathrm{f}}$ of 0.63 and 0.19 for $\mathrm{TH}$ and $\mathrm{MH}$, respectively, in a run distance of $8 \mathrm{~cm}$. The linear regression analysis for the calibration plots produced $\mathrm{r}^{2}=0.993$ and $\mathrm{r}^{2}=0.991$ for $\mathrm{TH}$ and $\mathrm{MH}$, respectively. 


\subsection{Mobile Phase Characteristics}

Several experiments were performed to get a sharp chromatographic peak that doesn't interfere with baseline separation peaks. During this trial, the flow rate of the mobile and solvents ratio of the mobile phase changed many times. For ideal separation of the drugs, AR grade methanol: ammonium sulphate $(0.5 \% \mathrm{w} / \mathrm{v})$ : triethylamine $(9: 2.7: 0.5 \mathrm{v} / \mathrm{v} / \mathrm{v})$ proved to be the best combination because the chromatographic peak obtained was better solved and free of tailing and fronting shown in Figure S1.

\subsection{Method Validation}

\subsubsection{Linearity}

The linearity of response for the present method was determined by analyzing TH and MH's standard solution in the range of 4-28 ng/band and 200-700 ng/band, respectively, as shown in Figure S1 Correlation coefficients were found to be $\mathrm{r}^{2}=0.992$ and 0.991 , respectively. The linear regression equation was $y=2.6412 x+1803.60$ for TH and $y=6.3369 x+261.03$ for MH, where $y$ is the peak area and $x$ is the concentration in $\mathrm{ng} / \mathrm{band}$ (see Table S1, and Figure S2, in supporting information)

\subsubsection{Accuracy}

Recovery experiments were conducted to determine the accuracy of the method for the quantification of $\mathrm{TH}$ and $\mathrm{MH}$. Recovery of the method was checked at around working concentrations for target compounds in triplicate. Average recoveries were determined as $99.75 \%$ for $\mathrm{TH}$ and $98.9 \%$ for $\mathrm{MH}$ (Table 1 and Table 2).

Table 1. Accuracy data of TH $(n=3)$

\begin{tabular}{|c|c|c|c|c|c|c|c|}
\hline $\begin{array}{c}\text { Level } \\
(\%)\end{array}$ & $\begin{array}{c}\text { Sample } \\
\text { Concentration } \\
\text { (ng/band) }\end{array}$ & $\begin{array}{l}\text { Standard } \\
\text { added } \\
\text { (ng/band) }\end{array}$ & $\begin{array}{c}\text { Total } \\
\text { concentration } \\
\text { (ng/band) }\end{array}$ & $\begin{array}{c}\text { Amount } \\
\text { found } \\
\text { (ng/band) }\end{array}$ & $\begin{array}{c}\text { Recovery } \\
(\%)\end{array}$ & $\begin{array}{c}\text { Mean area } \pm \\
\text { SD }\end{array}$ & $\begin{array}{c}\% \\
\text { RSD }\end{array}$ \\
\hline 50 & 12 & 8 & 20 & $\begin{array}{l}7.98 \\
7.99 \\
7.96\end{array}$ & $\begin{array}{l}99.75 \\
99.89 \\
99.50\end{array}$ & $99.72 \pm 0.20$ & 0.203 \\
\hline 100 & 12 & 12 & 24 & $\begin{array}{l}11.96 \\
11.97 \\
11.95\end{array}$ & $\begin{array}{l}99.66 \\
99.75 \\
99.58\end{array}$ & $99.66 \pm 0.09$ & 0.090 \\
\hline 150 & 12 & 16 & 28 & $\begin{array}{l}16.01 \\
15.98 \\
15.96\end{array}$ & $\begin{array}{l}100.06 \\
99.87 \\
99.75\end{array}$ & $99.96 \pm 0.095$ & 0.095 \\
\hline
\end{tabular}

Table 2. Accuracy data of MH ( $n=3)$

\begin{tabular}{|c|c|c|c|c|c|c|c|}
\hline $\begin{array}{c}\text { Level } \\
(\%)\end{array}$ & $\begin{array}{c}\text { Sample } \\
\text { Concentration } \\
\text { (ng/band) }\end{array}$ & $\begin{array}{c}\text { Standard } \\
\text { added } \\
\text { (ng/band) }\end{array}$ & $\begin{array}{c}\text { Total } \\
\text { concentration } \\
\text { (ng/band) }\end{array}$ & $\begin{array}{c}\text { Amount } \\
\text { Recovered } \\
\text { (ng/band) }\end{array}$ & $\begin{array}{c}\text { Recovery } \\
(\%)\end{array}$ & Mean \pm SD & $\begin{array}{l}\text { RSD } \\
(\%)\end{array}$ \\
\hline 50 & 300 & 200 & $\begin{array}{l}500 \\
500 \\
500\end{array}$ & $\begin{array}{l}196.21 \\
197.55 \\
198.99\end{array}$ & $\begin{array}{l}98.10 \\
98.77 \\
99.49\end{array}$ & $98.98 \pm 0.69$ & 0.70 \\
\hline 100 & 300 & 300 & $\begin{array}{l}600 \\
600 \\
600\end{array}$ & $\begin{array}{l}296.11 \\
298.06 \\
295.08\end{array}$ & $\begin{array}{l}98.70 \\
99.35 \\
98.36\end{array}$ & $98.80 \pm 0.50$ & 0.59 \\
\hline 150 & 300 & 400 & $\begin{array}{l}700 \\
700 \\
700\end{array}$ & $\begin{array}{l}396.80 \\
398.28 \\
397.55\end{array}$ & $\begin{array}{l}99.20 \\
99.57 \\
99.38\end{array}$ & $99.38 \pm 0.18$ & 0.18 \\
\hline
\end{tabular}




\subsubsection{Precision}

Intra-day precision -the RSD \% was calculated, and it was found to be $0.82-1.01$ and $0.93-0.1 .15$ for $\mathrm{TH}$ and $\mathrm{MH}$, respectively, which are well within the acceptable criteria of not more than 2.0. The result was shown in Table 3.

Table 3. Intraday precision data of TH and MH for HPTLC method $(\mathrm{n}=6)$

\begin{tabular}{cccccc}
\hline \multicolumn{2}{c}{ Conc. $($ ng/band $)$} & \multicolumn{2}{c}{ Peak area $($ Mean \pm SD) } & \multicolumn{2}{c}{ \%RSD } \\
\hline TH & MH & TH & MH & TH & MH \\
\hline 8 & 200 & $1800.36 \pm 18.36$ & $1537.66 \pm 16.31$ & 1.01 & 1.06 \\
12 & 300 & $1841.66 \pm 15.27$ & $2228.60 \pm 25.76$ & 0.82 & 1.15 \\
16 & 400 & $1850.00 \pm 18.02$ & $2946.73 \pm 27.53$ & 0.97 & 0.93 \\
\hline
\end{tabular}

Inter-day precision-the RSD \% was calculated, and it was $1.06-1.13$ and $1.19-1.27$ for TH and $\mathrm{MH}$, respectively, which are well within the acceptable criteria of not more than 2.0. The result was shown in Table 4.

Table 4. Interday precision data of TH and MH for HPTLC method ( $\mathrm{n}=6)$

\begin{tabular}{cccccc}
\hline \multicolumn{2}{c}{ Conc. $($ ng/band) } & \multicolumn{2}{c}{ Peak area $($ Mean \pm SD) } & \multicolumn{2}{c}{ \%RSD } \\
\hline TH & MH & TH & MH & TH & MH \\
\hline 8 & 200 & $1808.00 \pm 19.52$ & $1539.00 \pm 18.52$ & 1.13 & 1.2 \\
12 & 300 & $1857.40 \pm 19.76$ & $2252.00 \pm 28.74$ & 1.06 & 1.27 \\
16 & 400 & $1868.00 \pm 21.28$ & $2949.60 \pm 35.30$ & 1.07 & 1.19 \\
\hline
\end{tabular}

\subsubsection{Specificity}

The purity of the peaks was confirmed by a high degree of correlation, i.e., 0.99 , by comparison of peaks of MH and $\mathrm{TH}$, which was scanned at peak end, peak apex, and peak start. The correlation spectra of sample drugs with standards were shown in Figure 3, while TH and MH's peak purity's demonstrated in Table 5. The correlation obtained was $0.9995,0.9998$ for $\mathrm{MH}$ and $\mathrm{TH}$, respectively. Identity of the spots in overlay spectra of sample and standard confirmed the correlation and peak purity shown in Figure 4.

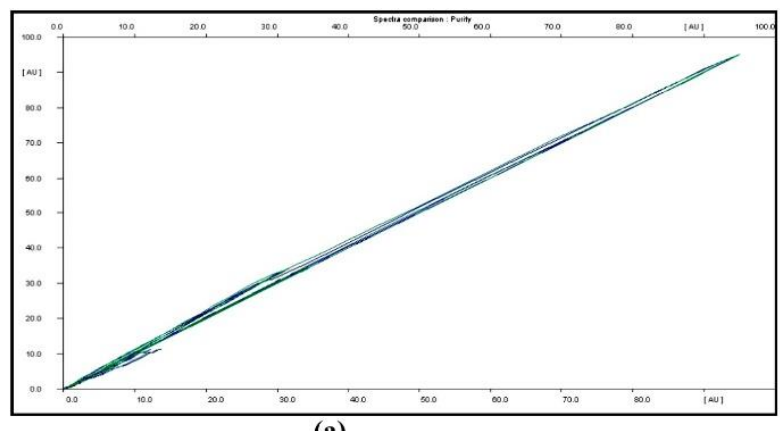

(a)

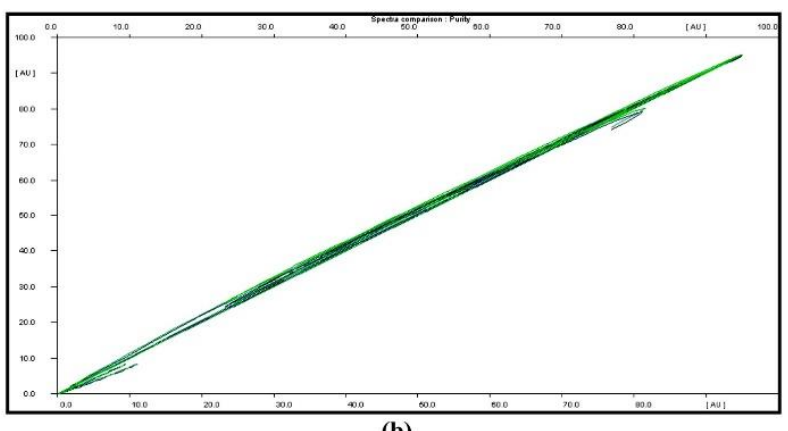

(b)

Figure 3. (a) Correlation spectra of $\mathrm{MH}$ from standard and sample solution (b) Correlation spectra of $\mathrm{TH}$ from standard and sample solution

Table 5. Peak purity of TH and MH

\begin{tabular}{ccccc}
\hline Sr. No. & Drug component & Type & r (S, M) & r (M, E) \\
\hline 1 & MH & Standard & 0.9997 & 0.9996 \\
2 & MH & Formulation & 0.9991 & 0.9994 \\
3 & TH & Standard & 0.9998 & 0.9997 \\
4 & TH & Formulation & 0.9997 & 0.9996 \\
\hline
\end{tabular}




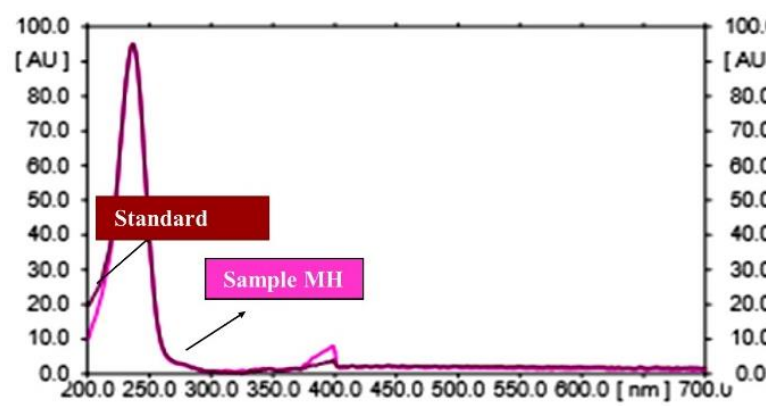

(a)

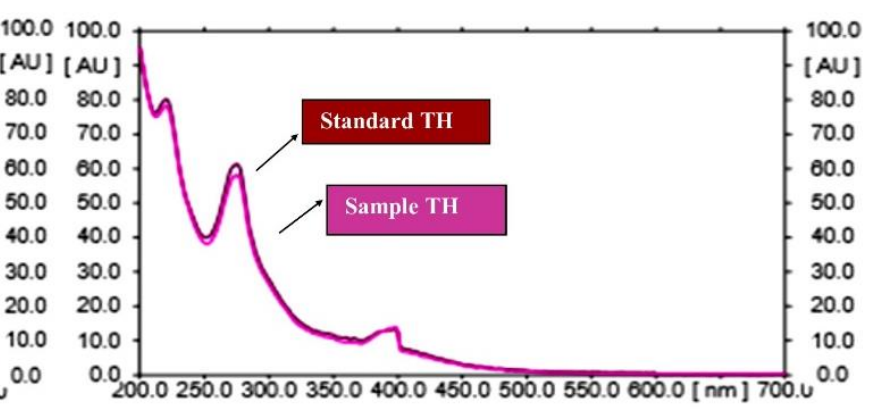

(b)

Figure 4. (a) Overlay spectra of MH from standard and sample solution (b) Overlay spectra of TH from standard and sample solution

\subsubsection{Limit of Detection (LOD) and Limit of Quantification (LOQ)}

LOD for TH was found $0.3 \mathrm{ng} / \mathrm{band}$ while $\mathrm{MH}$ was detected at a $27 \mathrm{ng} / \mathrm{band}$ concentration. LOQ for $\mathrm{TH}$ was $3 \mathrm{ng} / \mathrm{band}$, and $\mathrm{MH}$ was $85 \mathrm{ng} / \mathrm{band}$.

\subsubsection{Robustness Using QbD Approach}

Robustness was perfomed using Placket-Burman (PB) design to validate the HPTLC method considering a total of twelve experiments [17, 21]. In this design, seven HPTLC conditions were designed and analyzed (Table 6, 7). A combined standard solution of TH (12 ng/band) and MH (300 ng/band) was analyzed at each design of experiment. All the experiments were taken three times and performed in random order.

Table 6. Twelve - experiment Plackett-Burman (PD) design for seven factors

\begin{tabular}{cccccccc}
\hline List of & \multicolumn{7}{c}{ List of Factors } \\
\cline { 2 - 8 } Experiment & A & B & C & D & E & F & G \\
\hline $\mathbf{1}$ & -1 & 1 & 1 & -1 & 1 & 1 & 1 \\
$\mathbf{2}$ & 1 & -1 & -1 & -1 & 1 & -1 & 1 \\
$\mathbf{3}$ & 1 & -1 & 1 & 1 & -1 & 1 & 1 \\
$\mathbf{4}$ & 1 & 1 & -1 & 1 & 1 & 1 & -1 \\
$\mathbf{5}$ & 1 & 1 & -1 & -1 & -1 & 1 & -1 \\
$\mathbf{6}$ & -1 & -1 & 1 & -1 & 1 & 1 & -1 \\
$\mathbf{7}$ & -1 & 1 & -1 & 1 & 1 & -1 & 1 \\
$\mathbf{8}$ & -1 & 1 & 1 & 1 & -1 & -1 & -1 \\
$\mathbf{9}$ & 1 & -1 & 1 & 1 & 1 & -1 & -1 \\
$\mathbf{1 0}$ & 1 & 1 & 1 & -1 & -1 & -1 & 1 \\
$\mathbf{1 1}$ & -1 & -1 & -1 & -1 & -1 & -1 & -1 \\
$\mathbf{1 2}$ & -1 & -1 & -1 & 1 & -1 & 1 & 1 \\
\hline
\end{tabular}

Plackett-Burman (PB) design shown that method was robust. The obtained graphs presented in Figure 5. The Pareto graph shown in Figures 5 indicates the relationship of bar length to the estimated effect of that factors divided by the pseudo standard error defined by Lenth (Lenth's PSE). Based on the Pareto Chart, the effects of each factor were identified. Both main effects and terms of interaction are statistically negligible, as absolute values of main effects are below the critical p-value. (Table 8). 
Table 7. Plackett-Burman experimental design with seven factors for HPTLC

\begin{tabular}{clccc}
\hline $\begin{array}{c}\text { Factor } \\
\text { Label } \\
\text { code }\end{array}$ & \multicolumn{1}{c}{ Significant factor } & \multicolumn{2}{c}{ Modification Levels } \\
\cline { 3 - 5 } & & $(-)$ & $(\mathbf{0})$ & $(+)$ \\
$\mathbf{A}$ & $\begin{array}{l}\text { Modification in proportion of Methanol in mobile } \\
\text { phase composition (mL) }\end{array}$ & 8.8 & 9 & 9.2 \\
& $\begin{array}{l}\text { Altering the amount of Ammonium sulphate in mobile } \\
\text { phase composition (mL) }\end{array}$ & 2.6 & 2.7 & 2.8 \\
$\mathbf{C}$ & Deviation in the amount of Mobile phase volume & 12.1 & 12.2 & 12.3 \\
$\mathbf{D}$ & Altering in saturation time for TLC development (min) & 13 & 15 & 17 \\
$\mathbf{E}$ & Detection at different wavelength (nm) & 235 & 237 & 239 \\
$\mathbf{F}$ & Modifying in band width (mm) & 4 & 6 & 8 \\
$\mathbf{G}$ & Alteration in solvent run distance (cm) & 7.5 & 8 & 8.5 \\
\hline
\end{tabular}

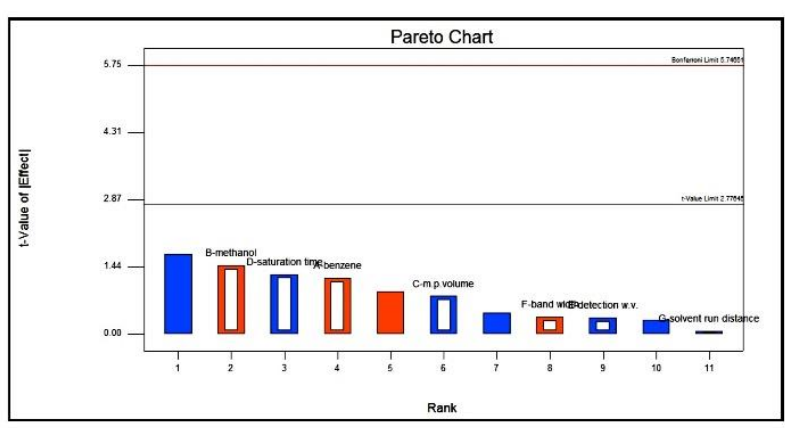

(a)

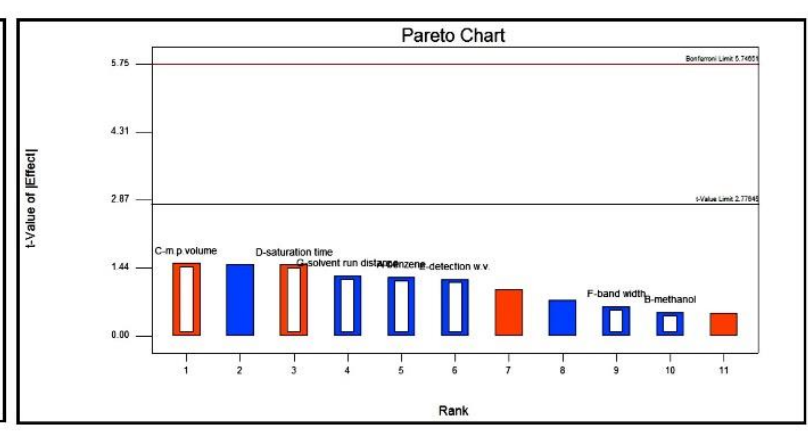

(b)

Figure 5. (a) Pareto chart ( $\mathrm{t}$-value vs effect) for $\mathrm{MH}$ and (b) Pareto chart ( $\mathrm{t}$-value vs effect) for $\mathrm{TH}$

Table 8. P-Value for robustness study

\begin{tabular}{ccc}
\hline Factor & \multicolumn{2}{c}{ P-Value } \\
\cline { 2 - 3 } & MH & TH \\
\hline A & 0.2997 & 0.2848 \\
B & 0.2180 & 0.6445 \\
C & 0.4668 & 0.2006 \\
D & 0.2721 & 0.2076 \\
E & 0.7468 & 0.2983 \\
F & 0.7386 & 0.5709 \\
G & 0.9604 & 0.2752 \\
\hline
\end{tabular}

P-Value: > 0.05, which means that the factor is significantly not affected by the response.

So here, no value is lower than 0.05 means the method is robust.

\subsection{Assay of Marketed Formulation by HPTLC Method}

The \% assay of $\mathrm{TH}$ and $\mathrm{MH}$ were calculated by taking five replicates of the test sample (Table 9). The \% mean assay of $\mathrm{TH}$ and $\mathrm{MH}$ were $99.99 \%$ and $100.08 \%$, respectively, which lies within the acceptable limit of 95-105\%, which shows that the method is applicable for marketed formulation analysis. 
Table 9. Assay of formulation (Tablet) by HPTLC method (Where, $n=5$ )

\begin{tabular}{cccccc}
\hline \multicolumn{2}{c}{$\begin{array}{c}\text { Labelled claim } \\
(\% \text { W/W })\end{array}$} & \multicolumn{2}{c}{ Peak area } & \multicolumn{2}{c}{ \%Assay } \\
\hline TH & MH & TH & MH & TH & MH \\
\hline $\mathbf{2 0}$ & 500 & 1836 & 2201 & 100.01 & 100.01 \\
$\mathbf{2 0}$ & 500 & 1833 & 2205 & 99.83 & 100.18 \\
$\mathbf{2 0}$ & 500 & 1834 & 2206 & 99.89 & 100.22 \\
$\mathbf{2 0}$ & 500 & 1833 & 2199 & 99.83 & 99.90 \\
$\mathbf{2 0}$ & 500 & 1835 & 2203 & 99.94 & 100.09 \\
& & & & 99.99 & 100.08 \\
& & MEAN & & 0.07 & 0.12 \\
& & \% RSD & & 0.07 & 0.12 \\
\hline
\end{tabular}

\section{Conclusions}

In a development of the HPTLC method for estimating TH and MH in tablet formulation, by trials and applying $\mathrm{QbD}$, it has shown the mobile phase composition of methanol: ammonium sulphate $(0.5 \%$ $\mathrm{w} / \mathrm{v})$ : triethylamine $(9: 2.7: 0.5 \mathrm{v} / \mathrm{v} / \mathrm{v})$ was more appropriate for simultaneous estimation of both the drugs and Plackett-Burman (PB) design indicate the method was robust and suitable for simultaneous estimation of $\mathrm{TH}$ and $\mathrm{MH}$. With these optimal conditions, baseline separation of both drugs with a reasonable resolution and optimized retention factor was achieved. The HPTLC method has been validated according to Q2 (R1) of the ICH Guidelines. The percentage of assay results for combination drugs is found to be within approval requirements (98-102\%); the result summary is shown in Table 10.

Table 10. Summary of results of HPTLC method

\begin{tabular}{lll}
\hline Parameters & TH & MH \\
\hline Linearity (ng/band) & $4-28$ & $100-700$ \\
Linearity equation & $y=2.6412 x+1803.60$ & $y=6.3369 x+261.03$ \\
Correlation co-efficient & 0.993 & 0.991 \\
Recovery study (Mean \%RSD) & 0.12 & 0.49 \\
Intraday Precision (\%RSD) & $0.82-1.01$ & $0.93-1.15$ \\
Interday Precision (\%RSD) & $1.06-1.07$ & $1.19-1.27$ \\
Repeatability Precision (\%RSD) & 0.74 & 0.79 \\
LOD (ng/spot) & 0.3 & 27 \\
LOQ (ng/spot) & 3 & 85 \\
Assay \% & 99.99 & 100.08 \\
\hline
\end{tabular}

This research involves systematically developing a simple, fast, accurate, and cost-effective HPTLC method for simultaneous TH and MH estimation. A better percentage of recoveries and proper validation showed the appropriateness and efficiency of the proposed analytical procedures. The optimized HPTLC method was validated as per ICH guidelines. All system suitability parameters are observed in optimal condition, and it was found with the range for $\mathrm{TH}$ and $\mathrm{MH}$ estimation. The validation analysis helped identify the best conditions by verifying that the approach was selective, specific, accurate, linear, precise, and robust. A statistical method was robust, and it can be design and proven by using PlackettBurman (PB) approach. The percentage assay values for formulations research were found to be between 98-102\%. In conclusion, a simple, selective, sensitive, and accurate HPTLC method was developed and validated under ICH guidelines Q2 (R1) for the routine quality of the dosage form analyzes containing TH and $\mathrm{MH}$. Consequently, this approach can be implemented successfully for the routine consists of dosage form analysis comprising $\mathrm{TH}$ and $\mathrm{MH}$ and is appropriate for regulatory submission under regulatory flexibility. 


\section{Acknowledgments}

The authors are thankful to Nirlife Healthcare, Nirma Ltd., Ahmedabad, India, for supporting this work. This work was carried out at Ramanbhai Patel College of Pharmacy, Changa, Gujarat, India.

\section{Supporting Information}

Supporting information accompanies this paper on http://www.acgpubs.org/journal/ journalof-chemical-metrology

\section{ORCID}

Mehul Patel: 0000-0002-2405-0243

Divya Patel: 0000-0001-9627-2745

Umang Shah: 0000-0001-6748-2137

Heta Kachhiya: 0000-0003-4534-6243

\section{References}

[1] S. K. Sharma, A. Panneerselvam, K. P. Singh, G. Parmar, P. Gadge and O. C. Swami (2016). Teneligliptin in management of type 2 diabetes mellitus, Diabet. Metab. Syndr. Obes. 9, 251-260.

[2] R. Sethi, S. Gandhi, D. Nitin and N. Sethiya (2015). Sethis HPLC: High-Performance Liquid Chromatography: Quantitative Analysis of Pharmaceutical Formulations, Volume 7.

[3] K. Sen, D. N. Hinsu, D. B. Sen, A. S. Zanwar, R. A. Maheshwari and V. R. Chandrakar (2016). Analytical method development and validation for simultaneous estimation of Teneligliptin hydrobromide hydrate and Metformin hydrochloride from it's pharmaceutical dosage form by three different UV spectrophotometric methods, J. Appl. Pharm. Sci. 6, 157-165.

[4] J.S. Surati and V.Patel (2018). Development and validation of dual wavelength UV spectrophotometric method for estimation of teneligliptin hydrobromide hydrate and metformin hydrochloride in combined dosage form, Pharma. Sci. Mon. 9, 301-306.

[5] H. Joshi and A. Khristi (2019). RP-HPLC method development and validation for the simultaneous estimation of teneligliptine hydrobromide hydrate (ten) and metformin hydrochloride (met) in tablet dosage form, Ind. Drugs, 56, 4956.

[6] R. Kant, R. B. Bodla, G. Kapoor and R. Bhutani (2019). Optimization of a single HPLC-PDA method for quantifying Metformin, Gliclazide, Pioglitazone, Dapagliflozin, Empagliflozin, Saxagliptin, Linagliptin and Teneligliptin using central composite design, Bioorg. Chem. 91, 103-111.

[7] M. Bhojani, K. Dadhania and S. Faldu (2012). Development and validation of RP-HPLC method for simultaneous estimation of furosemide and spironolactone in their combined tablet dosage form, J. Pharm. Sci. Biosci. Res. 2, 144-147.

[8] D.P. Lokhande (2019). Analytical method development and validation of teneligliptin by using RP-HPLC with ICH guidelines, Int. J. Trend. Sci. Res. Dev. 3, 259-263.

[9] V. Negi, V. Chander, R. Singh, B. Sharma, P. Singh and K. Upadhaya (2017). Method development and validation of meropenem in pharmaceutical dosage form by RP-HPLC, Ind. J. Chem. Technol. 24, 441-446.

[10] R. Vetapalem, R. P. Yejella and L. R. Atmakuri (2020). Development and validation of a stability indicating RP-HPLC method for simultaneous estimation of teneligliptin and metformin, Turkish J. Pharm. Sci. 17, 141-147.

[11] G. Srinivasu, C. Thirupathia, C. L. Narayanaa, C.P.Murthy and S. I. Siddiqui (2021). Development and validation of teneligliptin stereoisomers by HPLC using cellulose based immobilized polysaccharide chiral stationary phase, Curr. Pharm. Anal. 1-6. https://doi.org/http://dx.doi.org/10.2174/1573412917999201102204804.

[12] M. M. Annapurna, S. Almas, B. Rajasree and A. Narendra (2018). Stability indicating ultrafast liquid chromatographic method for the estimation of Teneligliptin (An Anti-diabetic agent), Asian J. Pharm. 12, S477-S483.

[13] Y. Kang, H. Jeong, T. Kim and K. Shin (2020). Bioanalytical method using ultra-high-performance, Molecules 25, 1-11.

[14] K. Chaudhari, J. Wang, Y. Xu, A. Winters, L. Wang, X. Dong, E. Y. Cheng, R. Liu and S. H. Yang (2020). Determination of metformin bio-distribution by LC-MS/MS in mice treated with a clinically relevant paradigm, PLoS One 15, e0234571.

[15] P. A. Shah, P.S. Shrivastav, P.G. Vanol and M. Sanyal (2018). Mechanistic study for the simultaneous determination of metformin and teneligliptin in human plasma using hydrophilic interaction liquid chromatography-MS/MS, Bioanalysis 10, 475-488.

[16] T. N. V. Ganesh Kumar, S. Vidyadhara, N. A. Narkhede, Y. Sai Silpa and M. Rajya Lakshmi (2016). Method development, validation, and stability studies of teneligliptin by RP-HPLC and identification of degradation products by UPLC tandem mass spectroscopy, J. Anal. Sci. Technol. 7, 1-8. 
[17] P. Jain, M. Patel and S. Surana (2013). Development and validation of stability-indicating high-performance thin-layer chromatography method for estimation of repaglinide in bulk and in pharmaceutical formulation, Acta Chromatogr. 25, 531-544.

[18] S. Malathi and T. Sivakumar (2014). Development and validation of HPTLC method for estimation of balofloxacin in bulk drug and in tablet dosage form, Int. J. Pharm. Tech. Res. 6, 392-395.

[19] M. M. Patel and H. D. Patel (2016). Development and validation of HPTLC method for simultaneous estimation of Terbinafine hydrochloride and Mometasone furoate in combined dosage form, J. Chil. Chem. Soc. 61, 2958-2962.

[20] D. Shah, K. Agrawal, F. Mehta and V. Patel (2018). Stability indicating HPTLC method for the estimation of anti-diabetic drug Teneligliptin, Curr. Pharm. Anal. 14, 1-11.

[21] A. A. Sagiroglu, C. Onal and S. E. Kepekci Tekkeli (2020). Liquid chromatographic analysis for the determination ofdeferasirox in pharmaceutical formulations and spiked plasma samples using dansyl chloride reagent, J.. Chem. Metrol. 14, 35-41.

[22] M. Topal (2020). Secondary metabolites of ethanol extracts of Pinus sylvestris Cones from Eastern Anatolia and their antioxidant, cholinesterase and $\alpha$-glucosidase activities, Rec.Nat.Prod. 14, 129-138.

[23] S. L. C. Ferreira, A. O. Caires, T. da S. Borges, A. M. D. S. Lima, L. O. B. Silva and W. N. L. Santos (2017). Robustness evaluation in analytical methods optimized using experimental designs, Microchem. J. 131, 163-169.

[24] M. Patel, J. Chauhan and H. Shah (2019). Development and validation of a high-performance thin-layer chromatography for the determination of terbutaline sulfate, bromhexine hydrochloride, and etophylline in pharmaceutical dosage form, Asian J. Pharm. Clin. Res. 12, 296-301.

[25] M. Patel, N. Vyas, H. Shah, U. Shah, A. Patel and A. Chokshi (2020). Analytical methods for simultaneous estimation of SGLT2 inhibitor and DPP-4 inhibitor in their combination for treatment of type 2 diabetes mellitus, Lett Appl NanoBioScience 10, 1799-1815.

[26] D. H. Shewiyo, E. Kaale, C. Ugullum, M. N. Sigonda, P. G. Risha, B. Dejaegher, J. Smeyers-Verbeke and Y. Vander Heyden (2011). Development and validation of a normal-phase HPTLC method for the simultaneous analysis of lamivudine, stavudine and nevirapine in fixed-dose combination tablets, J Pharm Biomed Anal. 54, 445-450.

[27] S. R. Chaudhari and A. A. Shirkhedkar (2020). Application of Plackett-Burman and central composite designs for screening and optimization of factor influencing the chromatographic conditions of HPTLC method for quantification of efonidipine hydrochloride, J. Anal. Sci. Technol. 11, 1-13.

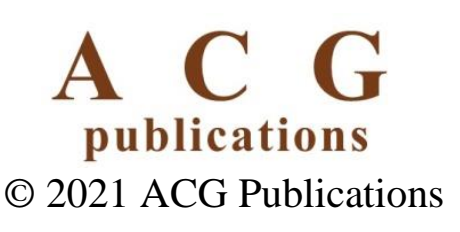

